\title{
Corpus
}

Archivos virtuales de la alteridad americana

Vol. 11, No. 1 | 2021

Enero / Junio de 2021

\section{Las falsas promesas de los monumentos}

Carlos Masotta

\section{OpenEdition}

\section{Journals}

Electronic version

URL: https://journals.openedition.org/corpusarchivos/4519

DOI: $10.4000 /$ corpusarchivos. 4519

ISSN: $1853-8037$

\section{Publisher}

Diego Escolar

Electronic reference

Carlos Masotta, «Las falsas promesas de los monumentos», Corpus [En línea], Vol. 11, №. 1 | 2021,

Publicado el 23 junio 2021, consultado el 03 julio 2021. URL: http://journals.openedition.org/ corpusarchivos/4519; DOI: https://doi.org/10.4000/corpusarchivos.4519

This text was automatically generated on 3 July 2021.

Licencia Creative Commons: Atribución-NoComercial 2.5 Argentina (CC BY-NC 2.5 AR) 


\title{
Las falsas promesas de los monumentos
}

\author{
Carlos Masotta
}

“Alguien demora en el jardín el paso del tiempo" Alejandra Pizarnik

Después de más de dos siglos de inauguraciones de monumentos nacionales ninguna de sus estatuas cumplió con la promesa de encarnarse en repúblicas democráticas, igualitarias o felices. Como si los dioses que le concedieron a Pigmalión el deseo de dar vida a la mujer amada que él mismo había esculpido sobre piedra en cambio hubiesen demorado esa acción dejándolo expectante y, finalmente, entre desesperanzado e indignado.

2 Forcemos más aun aquel mito clásico (para eso están los mitos). Supongamos que esos dioses fueran el Estado y que Pigmalión, no fuera un rey sino un simple ciudadano y que, cansado de esperar el milagro, arremetiera contra la estatua. El capítulo siguiente podría ser: a) restaurar la estatua y la creencia; b) crear una nueva escultura para olvidarse de lo sucedido; c) descreer de la relación entre estatuas y dioses.

La mayoría de los monumentos que en América Latina poblaron las plazas de sus principales ciudades en el siglo XIX se inspiraron en el espíritu neoclásico y civilizatorio proveniente de las tradiciones políticas y escultóricas europeas. Columnas, obeliscos y figuras ecuestres jugaron anacrónicamente con el prestigio de las antiguas ciudades-estado (Grecia y Roma) como una metáfora del nuevo poder del estado nación en construcción. Ante la falta de un lenguaje propio para nombrarlo, ese giro neoclásico fue un recurso común que hablaría por sí mismo en el nuevo continente. Con todo, la torsión que producía en su diseminación provocaba también pérdidas de los modelos que decía emular. En primer lugar, en su trasplante al nuevo continente, dejó de lado la tradición de las poblaciones indígenas, negras y criollas de los sectores populares, por lo tanto, la representación de lo público y lo comunitario en la que se embarcaba la primera monumentalística nacional y republicana se construyó bajo el principio de esa alteridad, silenciándola. En segundo lugar, el recurso metafórico y alegórico al que remitía además de ser interpretado solamente por sectores ilustrados exponía un resto 
de vacío de sentido sobre lo nombrado siempre en vacancia y tensión con aquel silenciamiento. En tal encrucijada, los monumentos parecen haberse elevado sobre bases precarias. Sin embargo, el proceso hegemónico al que pertenecen supo sortear estas contradicciones por medio de sus principales componentes: visual, espacial y temporal. El gigantismo y la toma de espacios dominantes impuso una autoridad de la escultura más allá de las interpretaciones literales de sus figuras. Asimismo, la construcción de un espacio solemne inscribe una temporalidad singular que, de la misma manera que el gigantismo, trasciende la historia específicamente narrada.

En resumen, los monumentos, con sus formas, dimensiones y topografías son constructores de temporalidad. Se muestran siempre asociados al pasado, pero guardan en su interior un programa a futuro y una promesa para la sociedad que habitan. Tal vez, el poder de su magia consiste en saber compaginar esos dos principios tan contrastantes: la piedra y el tiempo. En este sentido, la duración, que parece ser su principal promesa, es también su mayor debilidad. El derribo y las impugnaciones de los monumentos vuelca sobre la sociedad que los ha elevado una inquietante duda: esas moles ¿no eran eternas?

5 La impugnación de monumentos en la Argentina actual tiene un vínculo estrecho con un espacio característico creado en la ciudad de Buenos Aires hacia finales de 1880 . Se trata del trayecto de la Avenida de Mayo (aproximadamente 1000 metros) rematado en sus extremos por las sedes del Poder Ejecutivo (Casa de Gobierno) y Legislativo (Palacio del Congreso), respectivamente. Se lo conoce como eje cívico-monumental y, efectivamente, fue realizado con el espíritu de inscribir en el espacio urbano de la capital la forma de organización política nacional. Fue hecho con los medios propios de la modernización a los que la ciudad se entregaba: apertura de avenidas, grandes construcciones con alegorías para los edificios públicos y monumentos en las plazas de sus extremos. ${ }^{1}$

6 Dada su sofisticación y redundancia son los poderes del Estado los que parecen querer hablar allí por sí solos. En su origen, el conjunto se resolvería con el uso de ese espacio como escenario de actos oficiales donde la población les rindiera culto periódicamente. Pero el carácter aristocrático de tal dispositivo fue intervenido históricamente por la protesta social que supo ocupar el mismo espacio con manifestaciones multitudinarias. Ellas demuestran, hasta el día de hoy, que el eje cívico-monumental, sin deshacerse de su función inicial, es a su vez objeto de crítica e interpelación expresándose sobre esa traza las voces que esta última, con su parafernalia, parece haber querido acallar.

7 A continuación, comentaré algunos casos de impugnación de monumentos que pertenecen a este eje y en los cuales es posible observar la expresión de aquella tensión singular entre promesa y reclamo. 


\section{Colonismo}

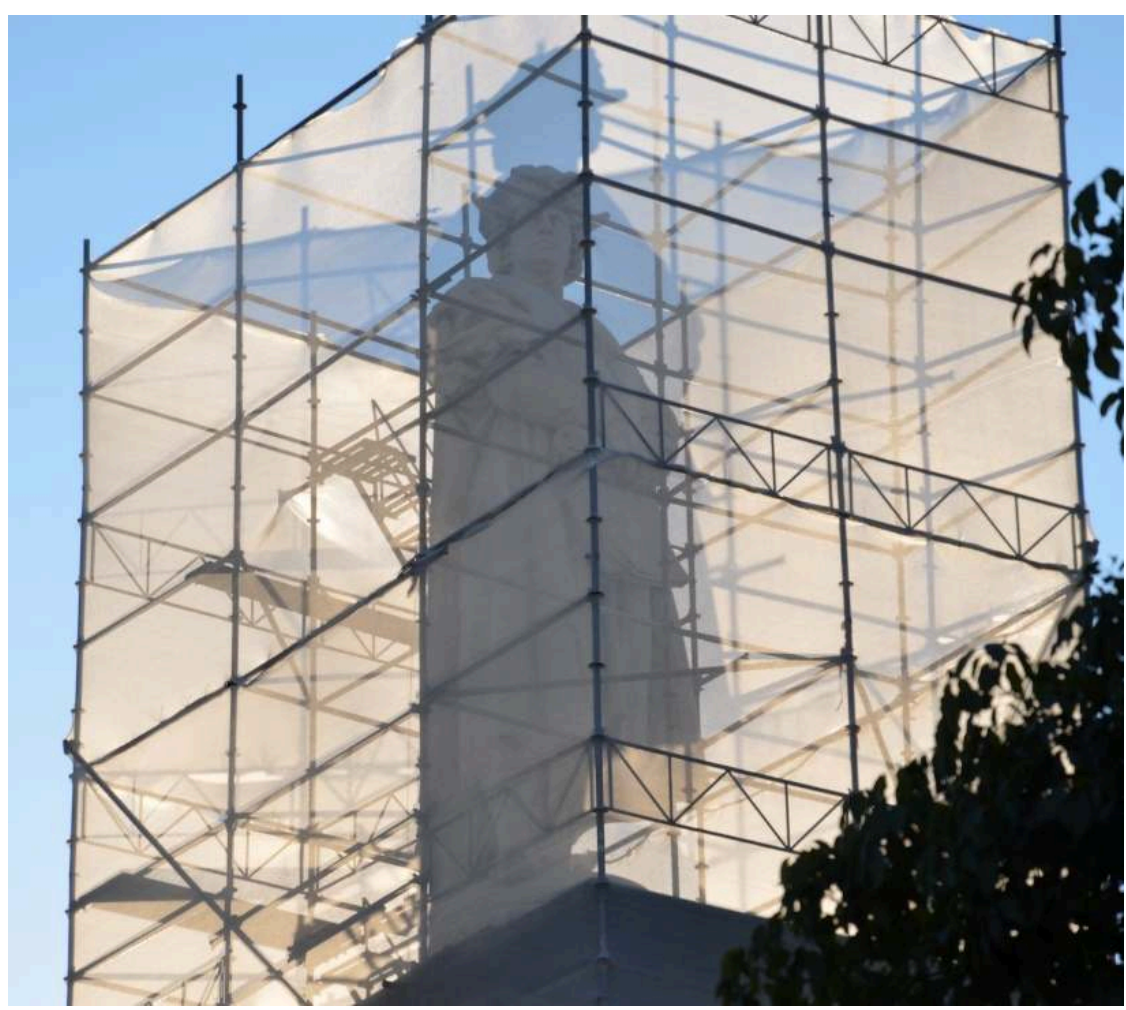

Imagen $\mathrm{N}^{\circ} 1$. Estatua de Cristóbal Colón en Buenos Aires en 2013 durante las obras de desguace para su relocalización. Foto del autor.

En 2013 se generó una polémica en torno a la relocalización, impulsada por el gobierno nacional, de la imponente estatua de Cristóbal Colón que desde 1921 se erigía en el extremo norte del principal eje monumental de la ciudad de Buenos Aires. Ese año, la mole de mármol fue desguazada a la espera de un nuevo destino. En 2015 el lugar que dejó vacante fue ocupado por un gran monumento a Juana Azurduy donado por el gobierno de Bolivia. Las elecciones presidenciales de ese año produjeron el cambio de signo político en el gobierno nacional y en 2017 la estatua de Juana Azurduy fue relocalizada (desde entonces el espacio fue ocupado por una pista de aterrizaje para helicópteros destinada a la Casa de Gobierno). Finalmente, en 2020, mientras en muchos países de América y Europa se daba una ola de acciones contra las estatuas de Colón por manifestaciones antirracistas, el gobierno de la ciudad de Buenos Aires reinauguró la vieja estatua en un nuevo punto periférico de la ciudad, frente a la costa del Río de la Plata. Esta especie de coreografía monumental que se debate entre eurocentrismo y latinoamericanismo muestra, por un lado, la vitalidad de la figura colombina y, con ella, la del viejo lenguaje que los monumentos aun practican en el espacio urbano. $\mathrm{Al} \mathrm{mismo}$ tiempo, expresa la dificultad de superar a ambos.

Que el fin del proceso de relocalización de la estatua en Argentina coincida con el auge de aquellas protestas no fue un hecho casual. La centralidad del monumento colombino en uno y otro caso es una cita que remite a un único proceso a la vez global, regional y local que si ha tenido ahora la fuerza de conmover los pesados cimientos de tal iconografía monumental es porque sus raíces son más profundas que las de la polémica actual decolonial, y a su vez más moderna, que la del colonialismo español. 
10 En efecto, tal profundidad parece remitir al período del colonialismo propio de la expansión europea de los siglos XV al XVIII, del cual la figura de Colón sería uno de sus principales símbolos. Sin embargo, las estatuas a Colón fueron producidas cuando ese proceso hacía tiempo había sido desarticulado por el surgimiento de las repúblicas americanas iniciado hacia finales del siglo XVIII. En resumen, los monumentos que estamos comentando no fueron un producto del colonialismo, sino de lo que me gustaría denominar colonismo. Con este término me refiero al auge inédito que en el siglo XIX alcanzó la figura de Cristóbal Colón (historiografía, periodismo, literatura, exposiciones internacionales, monumentos) encaminado a un momento de clímax en torno al cuarto centenario del llamado "descubrimiento de América" en 1892 y con continuidad en las décadas posteriores.

11 El colonismo construyó sus fundamentos escrituralmente ${ }^{2}$ pero ubicó en la escultura y el monumento público sus bases más poderosas, espectaculares, duraderas y delirantes. El discurso de la nacionalidad que se inscribió monumentalmente en los países latinoamericanos estuvo preñado de colonismo. Con epicentros en Italia y España la versión monumental de Colón fue adoptada fervientemente por todas las naciones del nuevo continente, especialmente las latinoamericanas. Para 1893, 12 de los 23 monumentos al nuevo héroe que ya se contabilizaban, pertenecían a esas naciones. Por el colonismo, América descubrió a Colón.

12 La fiebre por el personaje y por su monumentalismo fue tal que, en su honor, llegó a planificarse el monumento más grande del mundo. Ese proyecto tuvo dos momentos. El primero fue ideado por el español José Marín Baldo y presentado en la Exposición Internacional de Filadelfia en 1876. Proponía la construcción de un museo que en forma de monumento estaría coronado por un globo terráqueo de 60 metros de diámetro con la figura de Colón sobre un barco, en su cumbre. En 1893 Alberto Palacio repitió la idea de un pedestal en forma de globo terráqueo en su proyecto para la Exposición Colombina de Chicago. Igual que el anterior se imaginaba al monumento con un gran museo en su interior pero, esta vez, el conjunto alcanzaría los 400 metros de alto. (Imagen $\mathrm{N}^{\circ} 2$ ) 




Imagen N². "Monumento colosal a la memoria de Cristóbal Colón", según "La llustración Española y Americana" (1890).

Además del tamaño proyectado, esa fórmula (el globo terráqueo como pedestal para la estatua de un individuo) era audaz. Ni la inventiva de Julio Verne hubiera llegado a tanto. Las alegorías barrocas que habían explotado ese recurso retórico-cartográfico habían optado por la reducción de la escala del globo en relación con el cuerpo humano. Esto permitía la escena del rey o la reina manipulándolo. 0 , en todo caso, sentándose sobre él como en algunos grabados se mostró a la alegoría de Europa. Pero el colonismo, que también supo usar ese viejo recurso, trajo algo nuevo que se delataba en el deseo de esos hiperbólicos monumentos. El globo como pedestal producía una escena de dominio más bizarra. El mundo se vería a los pies de la imagen de Colón pero el cambio de escala (el globo mayor que la estatua) intentaba salirse del recurso alegórico hacia el del efecto de realidad. Si la alegoría barroca había jugado con el globo terráqueo como escenificación del poder colonial, ahora algo de eso se mantenía pero, al mismo tiempo, se desarticulaba por el ingreso de un sujeto biográfico en su centro (o, mejor dicho, en su cumbre).

Las facetas del colonismo decimonónico fueron diversas y su alcance llegó a ser global. Su fuerza y fundamento no fue colonial sino nacional. Sus monumentos se erigieron a la gloria de las naciones y, en consecuencia, Colón pudo adoptarse como prócer patrio (parte del colonismo estuvo centrado en la discusión sobre sus orígenes: españoles, italianos, judíos, etc.). De alguna manera, la historia del descubrimiento evocada pudo ser una metáfora del imperialismo propia de la época que Eric Hobsbawm (1998) caracteriza como "La era del Imperio".

La estatua de Buenos Aires fue una donación de asociaciones y comerciantes italianos (fueron las comunidades de inmigrantes italianos las que realizaron festejos públicos en 1892). En 1905 se conoció al ganador del concurso de proyectos: el italiano Arnaldo 
Zocchi. La obra sería inaugurada en 1910 durante los festejos del centenario patrio argentino. La estatua de Colón como festejo de la nacionalidad Argentina requería también de un lugar simbólico y se decidió instalarla en uno de los frentes de la casa de Gobierno sobre la Plaza Colón alineándola con el eje cívico-monumental que comentamos arriba. El caso muestra el ingreso del colonismo al siglo XX, pues la estatua fue inaugurada finalmente en 1921. Su figura fue articulada con la de los próceres patrios con los que ya compartía espacios destacados también en ciudades de provincia y pequeños pueblos.

16 La estatua de Buenos Aires fue la más espectacular. Muestra a un gigantesco Colón parado sobre una columna sostenida por un pedestal con la forma de la proa de un barco empujado por alegorías de los poderes mitológicos que habrían impulsado su viaje. Como fue inscrito en una placa, la escena describe la partida del Puerto de Palos. El monumento fue el último en sumarse a la línea central del eje cívico-monumental mencionado y, de esta manera, fue como un golpe historicista que colocó a Colón a la cabeza de toda la serie que ahora lo precedía. El giro eurocéntrico no podía ser más elocuente porque el monumento escenificaba en las costas del Río de la Plata la partida desde España. Su relocalización casi un siglo después, en 2020, lo corrió definitivamente del eje cívico-monumental pero su nueva instalación sobre la costa ribereña volvió a imaginar al Río de la Plata como el punto de partida de aquella saga colonial.

17 La restauración de la estatua de Colón en Buenos Aires, en contraste con las intervenciones iconoclastas de las manifestaciones antirracistas de ese año en otros países, parece sugerir que la disputa tiene aun final abierto. Toda iconoclasia monumental, si se cancela sobre sí misma, puede confundir al símbolo con la cosa simbolizada. ¿La iconoclasia colombofóbica conducirá al final del colonismo? 


\section{"No soy tu musa"}

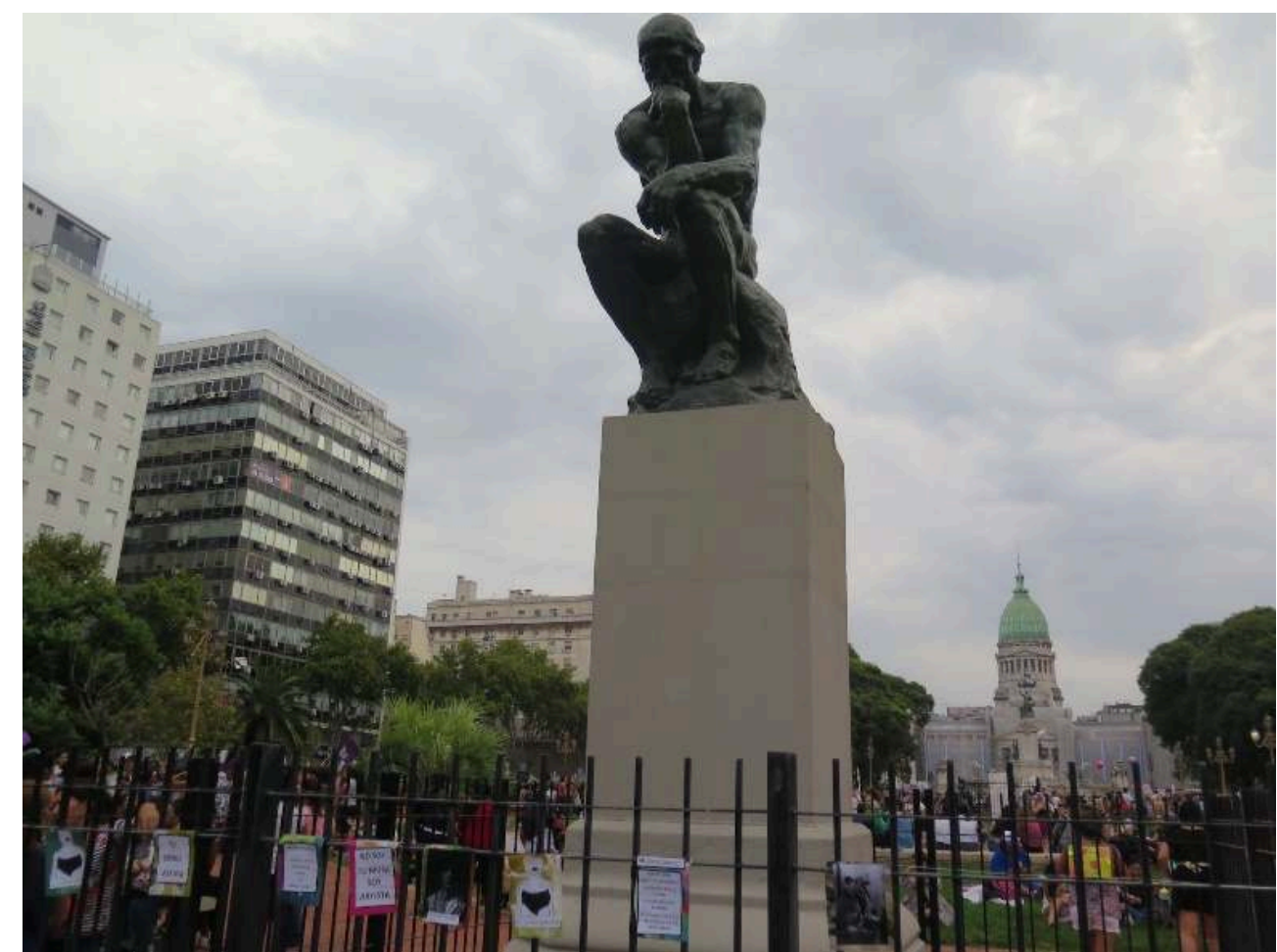

Imagen N³. Intervención sobre las rejas de "El Pensador" en la marcha del 8 de marzo de 2020. Foto del autor.

La complejidad de los monumentos se sustenta en la superposición que logran en ellos los campos de la política y el arte. El primero los asienta en el espacio público mientras el segundo los corporiza a través de la escultura. Efectivamente, entre ambos hay un objeto omnipresente de cuidadosa manipulación que es el cuerpo. La noción de antropofagia sugerida por Francisca Márquez para pensar las impugnaciones y derribo de monumentos es muy elocuente en este sentido, pues, en esos procesos se concentraría una forma del conflicto social que adopta la forma corporal inscripta en lo monumental para su despliegue y como centro de especial interés. La estrecha asociación que el monumento guarda con el cuerpo responde a la centralidad con que las relaciones de género son incorporadas por las esculturas en el espacio público.

En 2011 El Pensador de Rodin, instalado desde 1906 en la ciudad de Buenos Aires, amaneció pintado de un rosa intenso y con el símbolo de lo femenino dibujado en uno de sus brazos. La famosa escultura, más ornamental que patriótica, fue instalada sobre el mismo eje cívico-monumental que comentamos arriba. Sus intervenciones también responden a los sentidos reconducidos a la estatua por su ubicación sobre dicho eje, en este caso, en las cercanías del palacio del Congreso Nacional.

20 La intervención fue comentada por los medios de comunicación que rápidamente la caracterizó como "vandalismo" sin reparar en que la acción entablaba una polémica con el carácter de la misma obra. La famosa escultura muestra al cuerpo desnudo de un musculoso hombre sentado en actitud pensativa cercana a la tradicional pose asociada a la melancolía. La intervención anónima de 2011 pareció querer invertir los sentidos de género (masculino-pensamiento-razón) inscriptos en la estatua. El color rosa que alteró el grave y oscuro tono del bronce original y, en especial, el símbolo de lo 
femenino en el brazo del cuerpo masculino daban los indicios de que se trató de una acción feminista. Luego de ser restaurado, en 2015 la estatua volvió a ser cubierta con pintura roja. Estas acciones se realizaban en el contexto de la publicidad de casos cada vez más frecuentes de femicidios en Argentina. También en un momento de diversificación de formas de organización y protesta del movimiento de mujeres que tuvo un impacto decidido en los años siguientes y que tomó la plaza del Congreso como epicentro de sus manifestaciones. La respuesta del gobierno de la ciudad de Buenos Aires ante la intervención de El Pensador fue restaurar la escultura, elevar su pedestal y rodear el monumento con una reja.

En la multitudinaria marcha de mujeres realizada el 8 de marzo de 2020 fueron colocados sobre las rejas que protegían a $E l$ Pensador carteles con leyendas que denunciaban la historia de violencia machista que Rodin habría ejercido sobre su modelo y pareja, la escultora Camille Claudel: "No soy tu musa"; "tu genio asfixia"; "abuso psicológico". Tal intervención pareció menos contundente que la anterior aunque era certera al apuntar sobre los fundamentos involucrados en el proceso de creación artística de la obra. Como sea, un cuerpo manifestante y femenino ha tomado el espacio público expresándose entre los cuerpos esculpidos de los monumentos que lo habitan. En esa marcha y a pocos metros de distancia de esta escultura, un grupo de mujeres realizó una performance arrojándose al suelo. Con sus cuerpos amontonados, semidesnudos y con manchas simulando sangre, denunciaban los femicidios recreando una escena a la que ninguna de las estatuas de esa plaza podría referir. (Imagen $\mathrm{N}^{\circ} 4$ )

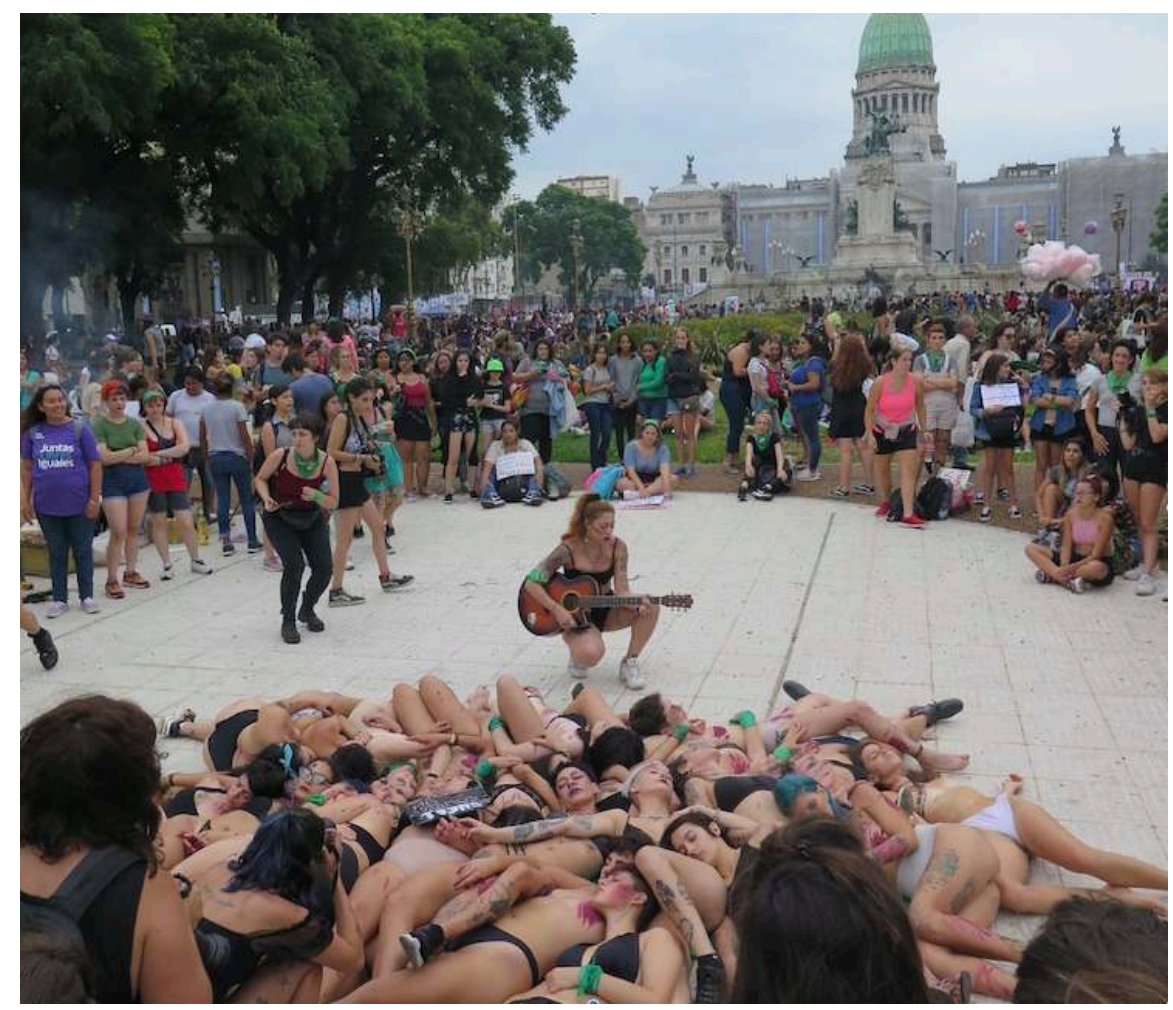

Imagen $\mathrm{N}^{\circ} 4$. Performance en la marcha del 8 de marzo de 2020. Foto del autor. 


\section{Un monumento en suspenso} sentido. Cambiando el gorro frigio por sus pañuelos y con la foto de sus hijos y familiares desaparecidos como escudos no festejaban a la nación en su monumento más emblemático, sino que, con sus movimientos, sin tocarlo, denunciaban los crímenes de Estado. Lo han puesto en un suspenso que lo interpela hasta la actualidad. Un suspenso temporal y espacial.

Para la historia argentina la relación monumento-cuerpo-género tiene un antecedente insoslayable: las rondas que, desde finales de la década de 1970, realizan todos los jueves las Madres de Plaza de Mayo en torno a la Pirámide de Mayo y que dieron origen a uno de los movimientos sociales más potentes en la historia reciente del país.

La Pirámide de Mayo fue el primer monumento que se erigió en la Argentina. La Primera Junta de gobierno ordenó construirlo en 1811 al cumplirse un año de su conformación independiente de la corona española. La Pirámide consistió en un rústico obelisco neoclásico, pero en 1865 fue elevada y coronada en su cumbre con la estatua de una Atenea patria que sostiene una lanza y un escudo con el blasón nacional y usa un gorro frigio, símbolo de los libertos. Desde entonces, y aunque no respeta el diseño original, esa es la figura emblemática del monumento que hoy es considerado como el señalamiento del kilometro 0 de la nacionalidad. La estatua alegórica de la libertad es identificada popularmente como la patria misma.

Para la segunda mitad del siglo XIX y primera del XX la alegoría femenina fue un recurso común para la representación sintética y a la vez erótica de la nación (la estatua de la Pirámide argentina lleva uno de sus pechos descubiertos). Fueron repetidas hasta el cansancio por la monumentalística del período. Su éxito y atractivo no solo residía en el erotismo del cuerpo femenino así representado, sino en el contrapunto entablado con las representaciones del cuerpo masculino con que los monumentos recreaban las figuras viriles de próceres y sujetos ilustres. En 1872, a unos pocos pasos de aquella Atenea patria se inauguró la estatua ecuestre del General Belgrano que lo muestra blandiendo un mástil con la bandera nacional que él había creado.

En sus primeros momentos, las Madres de Plaza de Mayo se concentraron entre los espacios de ambos monumentos para reclamar por sus hijos secuestrados por el terrorismo de Estado de la dictadura militar que entonces gobernaba el país. Ante la prohibición de concentraciones en el espacio público comenzaron a desplazarse por la plaza y en poco tiempo adoptaron el uso de sus emblemáticos pañuelos blancos y a la pirámide como centro de su movimiento circular. En los años siguientes esa figura inspiró a un movimiento multitudinario y a la vez se tornó símbolo. Uno de las agrupaciones de Madres de Plaza de Mayo lo adoptó como logo institucional (un círculo de pañuelos en torno a la Pirámide).

Las Madres con sus cuerpos encarnaron al de aquella Atenea, pero modificando su La pirámide fue creada como escenario para el ritual de Estado evocativo del nacimiento de la Argentina como nación. Las rondas de las Madres, con su reclamo y denuncia, intervinieron ese espacio a contrapelo. La forma y regularidad de sus movimientos, por decirlo así, enloquecieron al monumento (las Madres fueron llamadas por los militares "las locas de la plaza"). Los rituales de Estado imponen figuras devocionales ante los monumentos. El de las Madres es un ritual de 
interpelación. Interpela a la historia reciente, pero al hacerlo allí reenvía su reclamo y pregunta al origen mismo de la nacionalidad. Las rondas ponen en suspenso al monumento exponiendo y recordando cada jueves que el incumplimiento de su promesa ha producido en Argentina terrorismo de Estado. Pero el suspenso de la Pirámide también es espacial ya que, con el cuerpo vivo de las manifestantes, las rondas le crearon un nuevo pedestal (o un anti-pedestal) que la resignificó.

La conmoción profunda que el movimiento de Derechos Humanos realizó sobre el monumento (y sobre sus promesas) apareció graficada unos años atrás en una ilustración que el gobierno nacional difundió para el cuarenta aniversario del golpe cívico-militar de 1976 (Imagen $\mathrm{N}^{\circ} 5$ ). El dibujo mostraba a la antigua Atenea patria que, como si cumpliera el mito, se había encarnado. Había bajado de su alto pedestal y marchaba en ronda junto a las Madres.



ImagenNㄷ. Imagen conmemorativa para el 24 de Marzo, divulgada por el gobierno nacional en 2016. Dibujo: Henán Cappeletti

\section{BIBLIOGRAPHY}

Hobsbawm, E. (1998). La era del Imperio: 1875-1914. Madrid: Grupo editorial Planeta.

La Ilustración Española y Americana" (1890). Año XXXIV: 32. 


\section{NOTES}

1. La idea de un eje no fue solo figurada. Efectivamente, en las plazas que rematan los extremos, algunos de sus monumentos fueron alineados con exacta rectitud. Ellos son, en torno a la Casa de Gobierno, la estatua de Cristóbal Colón (hoy removida), la estatua del General Belgrano y la Pirámide de Mayo (primer monumento de la Argentina); en el otro extremo de la traza, continúan la misma línea, "El pensador", de Auguste Rodin y el Monumento a los Dos Congresos. 2. Uno de los impulsos principales del colonismo decimonónico fue precisamente la popular biografía ficcionalizada escrita por Washington Irving publicada en 1828.

\section{AUTHOR}

\section{CARLOS MASOTTA}

Consejo Nacional de Investigaciones Científicas y Técnicas, Argentina.

Correo electrónico: cmasott@hotmail.com 